\title{
Resilience to Resurgence: How to Grow Your Way Out of the Crisis
}

\author{
Mat Hughes (Loughborough University)
}

KEYWORDS: Entrepreneurship, Innovation, COVID-19, Resilience.

In this discussion, Professor Mat Hughes talks with Dr. Leonardo Lim, a tech scout, corporate scale-up builder, and international collaborator. Dr. Lim has extensive experience in consumer electronics, energy and green technology and has worked in innovation at $L G$ and Rolls-Royce. He is currently assisting United Kingdom and Korean SMEs to scale up through international tacit knowledge exchange.

We've known for some time it pays to be resilient during a crisis. But organizational resilience is really a state in which the firm is capable of insulating, protecting, or lessening the effects of a crisis on its business operations. It is not enough without recovery. What about resurgence? What can entrepreneurs and managers do to build on their resilience to achieve resurgent growth? Can a firm grow its way out of a crisis? This is the subject of this interview, which is part of a podcast series by Professor Hughes on managing, converting and overcoming uncertainty.

In these highlights of the podcast, Hughes and Lim discuss ways that entrepreneurs can manage and overcome uncertainty in times of crisis, and move from a state of resilience to a state of resurgence. To listen to the full podcast, click the link at the end of this article.

\section{Embracing Uncertainty}

PROFESSOR MAT HUGHES: In your experience as someone who works at the interface of the corporate world and SMEs, in what ways do you think these two groups can work together to move forward in the highly uncertain and volatile world that we now live in?

DR. LEONARDO LIM: There are key characteristics that determine the ability of any company to navigate crisis situations, such as the COVID-19 pandemic. Two of the most important are timely action and readiness for uncertainty. These characteristics are equally important regardless of whether the company belongs to the corporate world or is a small- and medium-size enterprise. A crisis situation often forces companies to embrace change and being able to act in a timely manner can set a company apart for success. Additionally, being able to act in a timely manner is tied to a company's readiness to embrace that change and uncertainty. To that end, companies that are more malleable fare better in managing crisis situations. It is also important for entrepreneurs and managers to understand that crisis management generally requires companies to rely on their core competencies to drive organic growth and deliver value. In turn, collaboration between corporations and small- and medium-size enterprises is most fruitful when both sides are willing and able to respond to change effectively.

\section{Collaborating successfully}

HUGHES: How do firms use existing relationships to move from resilience to resurgence?

LIM: There are several best practices that can help firms to collaborate and successfully leverage existing business relationships during uncertain times. Businesses must find unique advantages to compete on, and while price could be an important factor, in uncertain times the strength of relationships and alignment of values become much more important than price. As companies consider their existing business relationships, they should think about them from a broader perspective, rather than simply look at them through a transaction lens. Building trust with business partners is particularly important in navigating uncertainties. A good, trusting business partnership can push you to think critically about your business and provide impetus to creating much needed changes in business practices.

HUGHES: A good example of this is Plaza Premium
Copyright ( 2020 The Authors. Entrepreneur \& Innovation Exchange is published at EIX.org. This is an open access article under the terms of the Creative Commons Attribution-NoDerivs License, which permits use and distribution in any medium, provided the original work is properly cited and no modifications or adaptations are made. View EIX.org Authorship Terms at https://eix.org/terms
FamilyBusiness 
Group, the world's largest independent airport hospitality service provider. At the outset of the COVID-19 crisis, Plaza Premium Group commissioned its own report on the importance of good relationships with core stakeholders. Its intention was to set the narrative and tone to not only protect its business now but to ensure trust between the firm and its stakeholders in the future to encourage growth. As many airlines and travel companies are learning, you can't grow out of a crisis if your customers are wary of your practices or your key stakeholders have felt let down. Resurgence cannot come from the firm alone.

\section{Innovation and Momentum for Change}

HUGHES: What advice would you give to entrepreneurs, managers and corporate entrepreneurs on what they should and should not do in the near term (next 6 to 12 months)?

LIM: Business practices likely need to shift for a successful resurgence after the crisis period. It is also likely that innovation will be necessary to drive growth. Succeeding in uncertain times requires businesses to think outside the box. Businesses must be willing to realign priorities and reengineer their business practices. Additionally, after the pandemic, innovation and the momentum for change will ultimately drive resurgence, which will fuel growth in companies. The more adaptive and strategic companies can become, the greater is their potential to navigate uncertainty and come out stronger on the other side of the pandemic.

HUGHES: Businesses can innovate their products, services, or business models. In the pandemic, we've seen businesses having to switch aggressively to online services and retailing, which brings additional challenges in reshaping logistics, customer service, and consumer engagement. Retail has faced an especially heavy burden, with the best having taken their business quickly into new digital conversations with customers. Others, such as longstanding UK retail legend Marks \& Spencer, have struggled to rapidly and effectively implement an online selling platform (such as M\&S' vital food business). Other retailers pivoted quickly -especially clothing, fashion, and sports businesses -- to meet new types of demands. Some firms, especially family firms, moved towards ecology and community. For example, the Williams and Mercedes Formula One racing teams invested in green technology solutions and in manufacturing hospital equipment, respectively. Italian and French fashion houses moved to develop protective clothing.

\section{Takeaways}

So, what have we learned? Past success can create problematic inertial effects that undermine a business when faced with a crisis. Therefore, you must first examine your business' readiness to handle uncertainty. Where do rigidities and inertia occur, and how quickly can you take your products, services, or business model into new channels to reach customers in new or more novel ways? Second, it is important to understand that while timely action beats random action, any action beats no action. Relationships are especially important to helping a business adapt its ways of serving markets and in protecting its position. Third, define a to-do list that enables you to embrace change, and not simply "put out fires." Any crisis will bring opportunities to rethink what your business can do or should do moving into the future. For example, longstanding institutions have been forced to digitize during the pandemic. And now more than ever, customers are demanding better products and services and responsible business practices. Actions on these fronts can act as steps to move from a state of resilience to a state of resurgence.

The full discussion between Professor Hughes and Dr. Lim can be found at:

https://soundcloud.com/user-49751720/moving-from-r esilience-to-resurgence?in=user-49751720/sets/manag ing-uncertainty 